\title{
ANALYTICS OF MX AND NDMA, TWO DISINFECTION BYPRODUCTS, IN WATER
}

\section{P. ANDRZEJEWSKI ${ }^{*}$ J. NAWROCKI}

Received: 10/01/05

Accepted: 30/03/05

\author{
Department of Water Treatment Technology \\ Faculty of Chemistry, Adam Mickiewicz University \\ Drzymały 24, 60-163 Poznan, Poland
}

*to whom all correspondence should be addressed: Tel: +48 6182934 34; Fax: +48 618293400

e-mail: pandrz@amu.edu.pl

\begin{abstract}
MX (3-Chloro-4-(Dichloromethyl)-5-Hydroxy-2(5H)-Furanone) and NDMA (N,N-dimethyl-Nnitrosoamine) are disinfection by-products, which are formed during NOM's and other water containing precursors reaction with chlorine. Both, due to their potential carcinogenic and mutagenic properties were placed on the list of potentially health hazardous disinfection byproducts. Both of the compounds occur in drinking water at the ppt level.

An extensive review of international literature was the background of the presentation of state of the art concerns on MX and NDMA analysis.
\end{abstract}

\section{INTRODUCTION}

MX (3-chloro-4-(dichloromethyl)-5-hydroxy-2(5H)-furanone) and NDMA (N,N-dimethyl-Nnitrosoamine) are found as disinfection by-products, which are formed during NOM's and other water containing precursors reaction with chlorine. However, its histories as disinfection by-products are completely different.

The history of MX's discovery is closely connected to research on mutagenicity of water and sewage, especially those samples treated with chlorine used as an oxidant or disinfectant and the development of instrumental analysis, allowing for separation, identification and improved detection of analyzed compounds. During the late 70's, attention was drawn to the strong mutagenic activity of sewage from paper production, especially wood pulp bleaching (Holmbom et al.,1984). The one compound, which was separated from sewage from wood pulp bleaching and chlorinated waters containing humic substances, MX, was shown to have extremely high mutagenic activity. The mass spectra of this compound was obtained, its structure established and systematic name found to be 3-chloro-4-(dichloromethyl)-5-hydroxy-2(5H)-furanone. In 1987, the same compound was found by Kronberg et al. (Kronberg et al., 1987 and Kronberg et al., 1988) in tap water from a surface water intake disinfected with chlorine. Thus, MX is relatively a newly discovered compound and the new disinfection by-product.

As opposed to MX, nitrosamines and particularly NDMA, have been known as compounds for more than 100 years. However, the presence of NDMA in drinking waters was reported in the 1980's and 1990's (Jobb et al. 1995), recently, Choi et al. (Choi et. al., 2002) and Mitch et al. (Mitch et al., 2002) in 2002 reported that $\mathrm{N}$ nitrosodimethylamine is formed during the disinfection of water and sewage with chlorine, and they pointed to dimethylamine as the main NDMA precursor. 


\section{ANALYTICS OF MX AND OTHER HALOGENATED HYDROXYFURANONES IN WATER}

\section{1. $M X$ sources, formation and occurrence}

There are three forms of $\mathrm{MX}$ present at neutral $\mathrm{pH}$ in water: ring form, open ring form and isomeric form (E-MX). Transformation of one form to another depends strongly on the $\mathrm{pH}$ (Kronberg et al., 1988). The mutagenic activity of E-MX is much lower than the hydroxyfuranone form of MX. However, at low $\mathrm{pH}, \mathrm{E}-\mathrm{MX}$ isomerizes to $\mathrm{MX}$, a reason why this compound is also of great interest.

Research on the mutagenic activity of $M X$ has shown the extremely high mutagenic activity of this compound, comparable only to that of aflatoxins. MX is responsible for approximately $30-60 \%$ of the mutagenic activity in drinking water extracts. The presence of MX in tap water was confirmed in many countries and determined concentrations were from a few to approximately $100 \mathrm{ng} \mathrm{l}^{-1}$ (Andrzejewski et al. and cited inside, 2003).

The mutagenic activity of $M X$ and its common occurrence in drinking water caused the WHO's Third Edition draft of the Guidelines for Drinking Water Quality, the recommended health based value associated with a $10^{-5}$ risk level was $1.8 \mu \mathrm{gl}^{-1}$ (WHO, 2003). In the final version of latest Guidance for Drinking water quality, Third Edition WHO, on the list of disinfection by-products (page 193), the recommended value was replaced with the note: "occurs in drinking water at concentration well below those at which toxic effects may occur." Analytical difficulties in determining MX at such low concentrations was a significant reason for the WHO decision mentioned above (WHO, 2004).

The MX synthesis method introduced by Lalonde et al. (LaLonde et al. 1990) allowed for synthesis of other similar compounds, whose mutagenic activity was assessed, depending on their structure (LaLonde et al. 1994 and LaLonde et al. 1991). Kronberg et al. (Kronberg et al., 1991) synthesized the oxidized and reduced MX analogues and an oxidized form of E-MX isomer. These compounds were present in tap water at levels comparable to or higher than MX. Ox-MX and Ox-EMX showed no mutagenic activity in the Ames test. Red-MX, however, appeared to have mutagenic activity at a level of 80 rev/nmol, about 70 times lower than MX (assuming MX: $5600 \mathrm{rev} / \mathrm{nmol}$ (Kronberg et al., 1987)).

The structure of hydroxyfuranones with monochloro-, dichloro- and trichloromethyl groups in the C5 position were also the subject of investigation (Franzen et al., 1994). Several 5dichloromethyl- and one 5-monochloromethyl-compounds were found at a level of $45 \mathrm{ng} \mathrm{l}^{-}$

1 in extracts from tap water. All the compounds investigated were shown to have much lower mutagenic activity than did $\mathrm{MX}$ at a level of 0.3-1.5 rev nmol ${ }^{-1}$.

The brominated analogues of MX (BMX) were also investigated. Lalonde et al. (LaLonde et al., 1997) synthesized and investigated the mutagenic activity of several MX related compounds. An increase of mutagenic activity from $10^{2} \mathrm{rev} \mathrm{nmol}{ }^{-1}$ to $10^{3} \mathrm{rev} / \mathrm{nmol}$ in the case of dihalo- and trihalo-4-methyl-5-hydroxy-2(5) $\mathrm{H}$-furanones was observed and was found not to depend on the halogen atom.

Two out of the three brominated MX analogues, called BMX (Fig. 1), namely BMX3 and especially BMX2, were shown to be highly active mutagenic compounds. BMX-2 and BMX-3 appeared to be stronger mutagens than MX (LaLonde et al., 1997). BMX's presence in chlorinated waters containing bromides was indicated in Japan. Suzuki et al (Suzuki et al., 1995) reported, that all three BMX's were found in concentrations similar to MX.

Several groups of compounds were pointed to as MX precursors: lignines by Conrad et al. (Conrad et al., 1994), humic compounds by Kronberg et al. (Kronberg et al., 1988), Blacklund et al. (Blacklund et al., 1989, Blacklund et al., 1988) and Horth (Horth, 1990), phenols by Langvik et al. (Langvik et al. 1991), amino acids by Horth (Horth, 1990). Other compounds like syringaldehyde (4-hydroxy-3,5-dimethoxybenzaldehyde) (Chengyong et al., 2000) as well as acetosyringone, ferulic acid, 3-ethoxy-4-hydroxy-benzaldehyde, 3,4,5-trimethoxy-benzaldehyde, vanillin, tryptophan and tyrosine (Huixian et al., 1999) were found also as MX precursors in reactions with an excess of chlorine. 


\subsection{Compound structure vs. available analytical techniques}

The MX, E-MX, C5-halogenated hydroxyfuranone (C5-MHF) and BMX2 structures are shown of Fig.1.<smiles>O=C1OC(O)C(C(Cl)Cl)=C1Cl</smiles>

3-chloro-4-(dichloromethyl) -5-hydroxyfuran-2 $(5 H)$-one $(\mathrm{MX})$

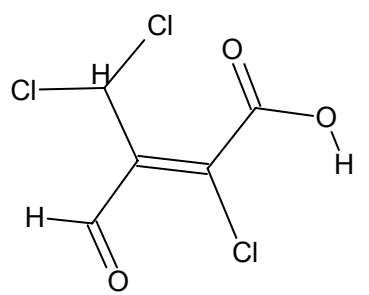

(2E)-2,4,4-trichloro-3-formylbut -2-enoic acid (E-MX)

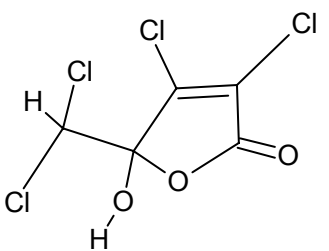

3,4-dichloro-5-(dichloromethyl) -5-hydroxyfuran-2 $(5 H)$-one (C5-HF)<smiles>O=C1OC(O)C(C(Br)Br)=C1Cl</smiles>

3-chloro-4-(dibromomethyl)-5hydroxyfuran-2(5H)-one (BMX-2)

Figure 1. MX, E-MX, C5-halogenated hydroxyfuranone (C5-MHF) and BMX2 structures.

$\mathrm{MX}$ is polar, very soluble in water; the molecular mass of the compound is $215.9 \mathrm{Da}$ and and it has water/octanol partition coefficients of $\log \mathrm{P}_{\mathrm{o} / \mathrm{w}}=1.13$ at $\mathrm{pH}=2$ (Vartiainen et al., 1991)

Determination of $M X$ in water is, however, very difficult because it is present in water at concentrations of a few $\mathrm{ng} \mathrm{I}^{-1}$ to several hundreds $\mathrm{ng} \mathrm{I}^{-1}$ and due to an unfavorably low water/octanol partition coefficient. On the other hand, the WHO, recommended no maximum admissible concentration values with information on health based values associated with a $10^{-5}$ risk level of $1.8 \mu \mathrm{g} \mathrm{I}^{-1}$ (WHO, 2004).

Thus, from the legislational point of view, e.g., application of an analytical method consisting of direct injection of water samples into HPLC coupled with an MS detector, meets the requirements concerning LOD and MX identification. However, the authors decided to describe only these analytical methods, which allow determination of MX at a level of a few ng ${ }^{-1}$.

An investigation of the structure of the $M X$ molecule suggests, that the following detection techniques can be used. The presence of double bonds of $\mathrm{C}=\mathrm{O}$ and $\mathrm{C}=\mathrm{C}$ allows application of a UV-VIS detector in the HPLC technique as well as photo ionization detector (PID) in the GC technique. On the other hand, the presence of three atoms of chlorine or one to three atoms of bromine in the MX or BMX molecule makes it possible to use the very sensitive electrone capture detector (ECD). However, in the authors' opinion, the usage of MS detection is the best solution, because the molecular mass of the compound (suitable retention time) as well as very characteristic fragmentation, obtained with the application of electron ionization, results from the presence of chlorine atoms in the MX molecule.

Mass spectra of MX derivatized with methanol is shown on Fig. 2

Derivatization procedure is a very important step in the analytical protocol of MX analysis, at least, where gas chromatography as the separation technique is used. The aim of this step is to decrease the polarity of the analyte to facilitate its gas-chromatographic analysis. The usual way for $M X$ determination in tap water is to extract compound from the water sample and the hydroxyl group of the $M X$ is then methylated to yield a methoxy group. Identification of the methyl pseudoester is done on the basis of its mass spectrum. Unfortunately, the two isotopic ions characterized by the highest intensities $(\mathrm{m} / \mathrm{z}=147$, 149) cannot be used due to their low specificity in complex water extracts. For qualitative and quantitative purposes, the triplet of isotopic fragments $\left[\mathrm{M}-\mathrm{OCH}_{3}\right](\mathrm{m} / \mathrm{z}=199,201$, 203) resulting from the presence of three chlorine atoms in $M X$ molecule is used 


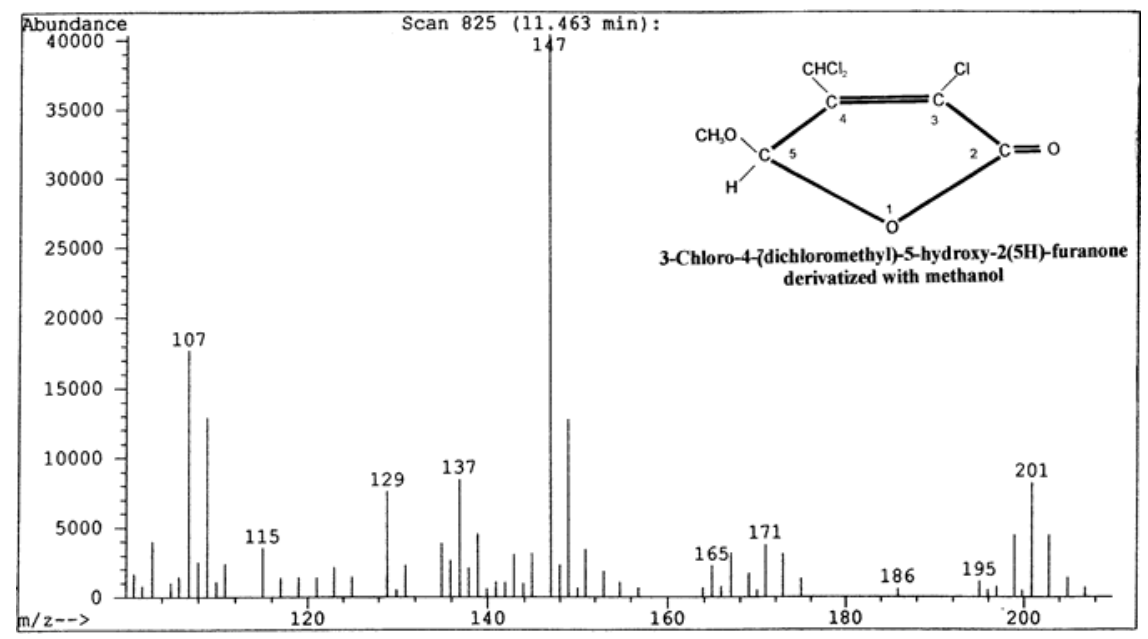

Figure 2. Mass spectra of MX derivatized with methanol

Due to an insufficient detector response factor, a preconcentration step can be employed as part of the analytical method. Analyte concentration factors should range from a thousand to several thousands. Additionally, optional application of an analyte cleaning procedure, can be considered.

Several analytical methods, which, in authors' opinion, meet requirements for $M X$ identification as well as LOD, on a level below MX concentration in water, are described below. The majority of the following analytical methods are based on applying SPE as the preconcentration technique and almost all of them employ a mass detector as the detection system.

\subsection{Analytical methods for the determination of $M X$ and other halogenated hydroxyfuranones in water}

Probably due to the lack of a maximum admissible concentration established for MX, no standardized analytical method for MX determination has yet been developed. Thus, the author decided to describe in detail the first of one developed by Kronberg et al. (Kronberg et al., 1988). This analytical method for the determination of MX and other chlorinated hydroxyfuranones has served as a kind of standardized method for many years. Up to today, the majority of newly developed analytical methods for the determination of MX and other chlorinated hydroxyfuranones have been based on the structure of this method.

A collected sample of 2-20 I volume was stored in order to remove chlorine. Following the introduction of mucobromic acid (MBA- 3,4-dibromo-5-hydroxy-2(5H)-furanone), an internal standard, the sample was adjusted to $\mathrm{pH} 2$ and subsequently introduced to a column filled with adsorbents Amberlit XAD-4 and XAD-8 (1:1). After passing through the column, the sample was dried and eluted with freshly distilled ethyl acetate. The extract was separated chromatographically (HPLC) in phases $\mathrm{C}_{8}$ and $\mathrm{C}_{18}$. After concentration, the sample was derivatized with $2 \% \mathrm{H}_{2} \mathrm{SO}_{4}$ in methanol. After concentration, the derivative, was subsequently analyzed by means of the GC/MS technique. The described procedure allows for both a quantitative and full mass spectrum analysis of the analyzed compound.

Resignation from fractionation with HPLC technique (a commonly used shortened analysis) requires, due to the high contamination of the sample, use of selective ion

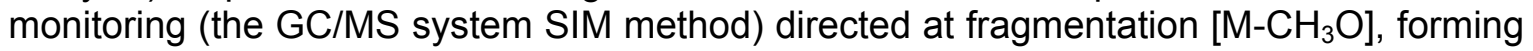
a triplet of isotope ions of $\mathrm{m} / \mathrm{z} 199,201$ and 203. Compound identification by this method is based on identify of retention time and isotope ion intensity ratio of the mentioned sample and its in standard use. 
Alternative techniques for analyte concentration were investigated by Vartiainen et al. (Vartiainen et al., 1987), Kronberg et al. (Kronberg et al., 1988), Onstad et al. (Onstad et al., 2005) and Andrzejewski (Andrzejewski, 1999).

Adsorption on Amberlite XAD-4 and XAD-8 (1:1) assures a relatively high recovery of MX from the matrix. Meier et al. (Meier et al., 1987) assessed MX recovery for this technique, based on fractionation with HPLC and identification with GC/MS, to be $57 \%$ for XAD-8 at $\mathrm{pH} 2$ and only $1.4 \%$ at $\mathrm{pH} 8$ (for this reason the $\mathrm{pH}$ of the analyzed water sample must be lowered). Schenck et al., by using the measurement of MX absorbance in UV light, assessed MX recovery at $92 \%$. Use of XAD-2 instead of XAD-8 reduces recovery to approximately $22 \%$ Schenck et al., (1990).

The authors' experience (Andrzejewski, 1999), made while analyzing MX in Poznań's municipal water by means of the above method, allows for a statement about the necessity of using high resolution mass spectrometry in MX analysis. In any case, this system was used by Kronberg et al. (Kronberg et al, 1988). Due to the level of background contamination derived from water contamination and adsorbent (Amberlit XAD-8), MX analysis with a low resolution MS detector was difficult and sometimes impossible. For the same reasons, application of ECD detection is also excluded. The superiority of mass spectrometry has also been confirmed by other authors (Charles et al., 1992). This and the cost of apparatus itself has resulted in the necessity of simplifying the MX determination method. Consequently, new methods have been introduced.

Vartiainen et al. (Vartiainen et al., 1987) investigated alternative techniques of analyte concentration. All research was carried out on drinking water collected from a lake and disinfected with chlorine. MX recovery was measured for $\mathrm{pH} 1$ and 11 , following the acidification and subsequent adjustment of sample $\mathrm{pH}$ to the latter higher $\mathrm{pH}$. $\mathrm{NaCl}$ concentration used for salting-out was 10 or $20 \%$. Process efficiency was measured by decreasing the sample's mutagenic activity before and after the process and compared with results obtained for adsorption on Amberlit XAD-4 and XAD-8 (1:1). Methods investigated included:

- Liquid-liquid extraction with dichloromethane with application of mechanical stirring.

- Liquid-liquid extraction in a mechanical homogenizer; double extraction with two portions of dichloromethane;

- Continuous extraction with dichloromethane or diethyl ether for 12,24 and $48 \mathrm{~h}$, respectively;

- Solid phase extraction on BLUE COTTON adsorbent:

- Application of adsorbent to the sample followed by stirring for $20 \mathrm{~h}$ (static adsorption);

- Use of a microcolumn with Blue cotton adsorbent and application of drops of the sample to the column (dynamic adsorption);

The adsorbent was subsequently eluted with methanol and concentrated ammonia water, or alternatively, with ethyl acetate.

Concentrates obtained after using the magnetic stirrer and homogenizer system showed mutagenic activity only when salting-out was applied, particularly when $20 \%$ of the salt was used. $15 \mathrm{~min}$ of stirring for $4 \mathrm{~h}$ allowed the generation of 5 to $25 \%$ of the mutagenic activity generated following $24 \mathrm{~h}$ of continuous extraction with dichloromethane. Application of double extraction with salting-out in the homogenizer enabled the collection of results similar to those obtained by continuous extraction. Application of Blue Cotton adsorbent gave no satisfactory results either.

Efficiency of liquid-liquid continuous extraction with salting-out $(20 \%$ of $\mathrm{NaCl})$ increased, although not strongly, with the time of extraction. Ethyl ether was found to be more efficient than dichloromethane.

Comparisons of results obtained for continuous liquid-liquid extraction and adsorption on XAD-4 and XAD-8 showed convergence. It must, however, be pointed out, that ethyl ether is known to be highly evaporative and dissolves relatively easily in water, even after 
salting-out. Its loss during a long process would significantly lower the efficiency of extraction. This does occur, despite the tightness of the container used.

Onstad et al. (Onstad et al., 2005) compared liquid-liquid extraction with ethyl acetate to extractions with n-hexane and MTBE. MX recoveries were comparable, each using a 5:1 single extraction ratio after derivatization of $500 \mu$ of extract with $\mathrm{BF}_{3} / \mathrm{MeOH}$. Ethyl acetate $(94 \%$ recovery) and MTBE $(83 \%)$ were much more successful than $n$-hexane $(7 \%)$ during $M X$ recovery from water. The recoveries of other halogenated hydroxyfuranones with MTBE extracted with LLE were investigated, as well.

Kronberg et al. (Kronberg et al., 1988) compared liquid-liquid extraction with ethyl ether and adsorption on an XAD-4 and XAD-8 (1:1) mixture. Mutagenic activity was the criterion of chlorinated natural water containing humic substances. Results obtained for triple liquid-liquid extraction at ratios of 1:4 and 1:8 were similar to those obtained for adsorption on Amberlite XAD-4 and XAD-8.

Rezemini et al. (Rezemini et al. 2002) compared MX recoveries from several SPE adsorbents (grafitized carbon, aluminia, Florisil, silica gel, XAD-4/XAD-8 (1:1) and $\mathrm{C}_{18}$ ) with typical extraction agents applied in LLE technique (diethyl ether, hexane, chloroform, ethyl acetate and dichloromethane). The influence of such parameters as solvent, $\mathrm{pH}$ and water sample salting out on MX recovery in SPE technique were examined. The influence of different extraction conditions (i.e., presence/absence of salt, $\mathrm{pH}$, solvent volume, number of extractions, time of extractions) in LLE technique were examined. MX recoveries obtained for applying the SPE technique, with grafitized carbon, Florisil and $\mathrm{C}_{18}$ as adsorbents, were low and did not exceed 9\%, however, Rezemini et al. (Rezemini et al. 2002) did not present results obtained for other adsorbents, especially XAD. Dichloromethane was found to be the best extraction agent for the MX concentration procedure with a recovery of $45-80 \%$. These results are different from those obtained by Vartiainen et al (Vartiainen et al., 1987).

Andrzejewski (Andrzejewski, 1999) investigated other alternative methods, based on the concentration of the sample through water evaporation under vacuum. MX stability at $60^{\circ} \mathrm{C}$ and $\mathrm{pH} 2$ yielded positive results (Asplund et al., 1995). Research on the recovery of $\mathrm{MX}$ and other chlorinated hydroxyfuranones was first carried out using high quality pure water modified with a mixture of hydroxyfuranones (the standard used: MCA, MCF, $\mathrm{CMCF}, \mathrm{MBA}$ and $\mathrm{MX}$ ) and following positive results, with tap water and standard added.

After $\mathrm{pH}$ adjustment to 2, the sample was concentrated under a vacuum and subsequently washed three-times with ethyl acetate, methanol and tetrahydrofuran, respectively.

Tetrahydrofuran and methanol were disqualified. The obtained results for ethyl acetate indicate an $80 \%$ to $90 \%$ recovery coefficient for $\mathrm{MX}$ and other chlorinated hydroxyfuranones, respectively. These results allow for the assessment of recovery coefficients for $\mathrm{MX}$ and other chlorinated hydroxyfuranones by means of the vacuum concentration method as very high.

Techniques aimed at increasing the detector response factor or selectivity were developed by Nawrocki et al. (Nawrocki et al., 1997; 1998; 1999; 2000; 2001a; 2001b), Fukui et al. (Fukui et al., 1990), Ogawa et. al. (Ogawa et. al., 1993) and Rezemini et al. (Rezemini et al., 2002).

$\mathrm{MX}$ is subjected to derivatization with methanol, as mentioned before, and subsequently analyzed in tap water extracts. This method is simple, requiring low reaction temperatures, offering easy separation of derivatization products from an excess of substrates, especially aggressive sulfuric acid.

Prior to GC/MS type MX determination in drinking water extracts, the compound is derivatized with acid methanol in order to convert the hydroxyl group to a methoxy one. The most abundant ion fragments in the mass spectrum of the pseudomethylester are ions at $\mathrm{m} / \mathrm{z} 147$ and 149 (Fig.2) formed by cleavage of the dichloromethyl group from the molecular ion. Despite the intensity of these ions, they are not specific enough for MX determination in the very complex drinking water extracts. Therefore, fragment ions at 199, 201, and 203 
have been used in GC/MS/SIM analysis. Disadvantages of this method include low relative abundances of cluster ions, which are $12.6 \%$ (199), $21.5 \%$ (201) and $13.2 \%$ (203) of ion $\mathrm{m} / \mathrm{z}$ 147. These ions are formed by loss of a methoxy group from the molecular ion. Due to a simultaneous loss of carbon monoxide from the [M-1] $]^{+}$ion (yielding $\mathrm{m} / \mathrm{z} 201$ ), the ratio of the ion cluster at 199 is not the theoretical one [100/97/32] Charles et al. (Charles et al., 1992) and Vartiainen et al. (Vartiainen et al., 1987) for a fragment containing three chlorine atoms, but the ratio is $58 / 100 / 61$. Only by using a high resolution mass spectrometer is it possible to distinguish between fragment ions produced by a loss of $\mathrm{OCH}_{3}$ and of $(\mathrm{H}+\mathrm{CO})$ (Charles et al., 1992). The main disadvantage in using fragment ions at 199,201 , and 203 , is that they are of rather low abundance and thus it is difficult to detect low MX amounts. A second drawback in this method concerns open-ring by-products derived from methylation. These by-products, called acetals, have been discovered for several chlorinated hydroxyfuranones (Andrzejewski et al. and cited inside, 2003).

It has therefore been decided to look for a new derivatization method by changing the alcohol, which would be capable of generating a characteristic, more intensive triplet in the GC-MS technique. Among the many alcohols examined, the best results were obtained for isopropyl and sec-butyl alcohol (two enantiomers were also examined). Isopropyl alcohol was found to be the best derivative factor for both MX (Nawrocki et al., 1997; 1998; 1999; 2000; 2001a; 2001b) and other similar hydroxyfuranones (Nawrocki et al., 2000 and Nawrocki et al., 2001a). Dominance of [M-(( $\left.\left.\left.\mathrm{CH}_{3}\right)_{2} \mathrm{CHO}\right)\right]$ fragmentation with isotopic ion triplets $\mathrm{m} / \mathrm{z}=198,9,200,9$ and 202,9 was evident.

The MX derivative derivatized with isopropyl alcohol was characterized by the highest of all examined response factor MSD detectors, representing the lowest detection threshold. The relatively high response factor of the MSD detector, compared to the MX methyl derivative, allowed application of a low resolution mass detector in MX analysis, with reduction, and even removal, of the problem with quantitative compound identification in the complicated matrix of tap water. As in the methyl derivative, it was the lone peak of one derivative that allowed for identification and quantitative analysis, when contamination interference was present.

In the case of sec-butyl alcohol, however, two chromatographic peaks with different retention times and intensity compared with adequate isotopic ions of the isopropyl derivative, were obtained (Nawrocki et al., 2001a). The existence of two peaks was due to the fact that carbon atom $\mathrm{C} 5$ in the $\mathrm{MX}$ molecule and other chlorinated hydroxyfuranones is an asymmetric carbon. There is also a chiral carbon atom C2 in the sec-butyl alcohol molecule. As a result of derivatization, four diastereoisomers (RR, RS, SR, SS) were formed. Two of their pairs were separated (Nawrocki et al., 2001b).

The MX derivatization with (trimethylsilyl)trifluoroacetamide (BSTFA) was proposed by Rezemini et al. (Rezemini et al, 2002). The derivatization process was performed in an injector after mixture of $\mathrm{MX}$ containing organic solvent extract and derivatization agent was injected into the injector itself. This derivatization technique coupled with the application of SPE technique as a preconcentration step and GC-MS technique as a separation/detection step allowed for the determination of MX at $3.0 \mathrm{ng} \mathrm{I}^{-1}$.

Techniques aimed at increasing the probability of $\mathrm{MX}$ identification as well as extending the list of potentially determined halogenated hydroxyfuranones (including BMX), were proposed by Zwinner et al. (Zwinner et al., 2001), Rantakokko et al. (Rantakokko et al., 2004) and Onstad et al. (Onstad et al., 2005).

Zwinner et al. (Zwinner et al., 2001) connected typical concentration and derivatization procedures (XAD resins and derivatization with methanol) with alternative GC-based method detection. The "typically" used GC-LRMS or GC-HRMS system was replaced by an ion-trap detector (ITD) with electron ionization (EI) and MS-MS fragmentation. This detection method allows detection of brominated hydroxyfuranones in concentrations below $1 \mathrm{ng} \mathrm{I}^{-1}$ and those of MX at approximately $2 \mathrm{ng} \mathrm{l}^{-1}$.

Rantakokko et al. (Rantakokko et al., 2004) evaluated different ways to reduce errors in quantification including comparison of gas chromatographic inlet systems, improved 
clean up of sample extracts, and preparation of calibration standards in the sample matrix. The optimized methods consists of sample cleaning with $\mathrm{C}_{18}$-resin in conjunction with SPE and GC-HRMS system with PTV splitless injection. Described method enables the determination of MX and BMX from $500 \mathrm{ml}$ of water sample with quantification limits of $1 \mathrm{ng} \mathrm{l}^{-1}$ or less.

Onstad et al. (Onstad et al., 2005) coupled LLE technique (MTBE as extraction agent was used) and derivatization with methanol $\left(\mathrm{BF}_{3} / \mathrm{MeOH}\right)$ with dual, GC-based, detection system. Two detectors were applied, micro ECD and ITD-MS/MS. The ITD-MS/MS detector system was used as a compound identity confirming system. This detection method allows detection of halogenated hydroxyfuranones in concentrations below $20 \mathrm{ng}$ $\mathrm{I}^{-1}$.

Although, in both cases, high efficiency equipment is required, these methods, based on collision-activated MS dissociation with an ion-trap detector, assures selectivity and sensitivity needed for determination of halogenated hydroxyfuranones in a very complex matrix of concentrated water samples.

An alternative of the GC/MS/SIM technique is a method based on highly sensitive ECD detection, proposed by Fukui et al. (Fukui et al., 1990) and Ogawa et. al. (Ogawa et. al., 1993). The derivatization of $M X$ with pentafluoropropyl alcohol was used. After derivatization, the sample was divided into two parts. One was analyzed directly with GC/ECD and the other irradiated with UV light in order to destroy the MX pseudoester thus formed. The sample was also subsequently analyzed with GC/ECD. The retention time peak was similar in the sample and in the standard, which disappeared after UV radiation, and was attributed to MX. According to the authors, the detection threshold of this method is approximately 3.5 times higher than the one following methylation, however Nawrocki et al. (Nawrocki et al., 1998) could not confirm that.

The HPLC technique is also used for MX determination. The sample of water was preconcentrated by the SPE technique and analyzed with HPLC/electrospray ionization/2-stage mass spectrometry. The calibration graph was linear for $<10 \mathrm{ng} \mathrm{I}^{-1}$, and the detection limit was $0.2 \mathrm{ng} \mathrm{l}^{-1}$ with a $20 \%$ error (Umetani et al., 1987).

MX stability during GC injection was investigated by Coleman et al. (Jolley et al., 1990). They investigated the degradation of MX during sample injection with a "hot needle" in the GC/MS system. Thermal decarboxylation of MX occurs at high injector temperatures (approximately $250^{\circ} \mathrm{C}$ ) with formation of 2-chloro-4-(dichloromethyl)propenal as a product. This process can be rejected by decreasing the injector temperature to a level of $180-200^{\circ} \mathrm{C}$.

The herein presented review of analytical methods for $M X$ determination, shows that the best one should consist of preconcentration of the water sample with Amberlite XAD resins, derivatization with methanol or isopropanol and GC analysis with either a low or high resolution mass detector.

\section{ANALYTICS OF NITROSAMINES IN WATER}

\subsection{Nitrosamines - sources, formation and occurrence}

Secondary nitrosamines like $\mathrm{N}$-nitrosodimethylamine (NDMA), $\mathrm{N}$-nitrosomethylethylamine (NMEA), N-nitrosodiethylamine (NDEA), N-nitrosodi-n-propylamine (NDnPA), N-nitrosodin-butylamine (NdnBA) and $\mathrm{N}$-nitrosodi-n-phenylamine (NDnPhA) are highly mutagenic compounds that are suspected of carcinogenic activity on the human body. The US Environmental Protection Agency (US EPA) has classified these compounds in group B2 thus indicating their probable carcinogenic effect on humans. For the three of them, i.e., NDMA, NMEA and NDEA, maximum admissible concentrations in water were established at very low concentration levels, i.e., at $7 \mathrm{ng} \mathrm{l}^{-1}$ (NDMA), $20 \mathrm{ng} \mathrm{l}^{-1}$ (NMEA) and $2 \mathrm{ng} \mathrm{l}^{-1}$ (NDEA) with risk estimation of $10^{-5}$, respectively (US EPA, 2005).

Rocket fuel (incomplete oxidation of hydrazines) (Gunnison et al., 2000), polymers, plasticizers, batteries and other industrial products can be pointed out as the main anthropogenic sources of nitrosamines (Richardson, 2003). On the other hand, microbial 
transformation of $\mathrm{N}$-precursors within feedlots is the main natural source of nitrosamines within the environment (Gunnison et al., 2000).

Nitrosamines are widespread in the environment. Their appearance has been confirmed in drinking water (Jobb et al. 1995), groundwater (mainly that supplied by recharged water) (Mitch et al., 2002), beers, meats, cheeses, pickles, human digestive activity in vitro and tobacco smoke (Gunnison et al., 2000).

Until the year 2002, knowledge concerning the formation of nitrosamines was based on the mechanism where secondary alkylamines reacted with nitrite (Wunsch et al., 1979).

Choi et al. (Choi et. al., 2002) and Mitch et al. (Mitch et al., 2002) in 2002 reported that Nnitrosodimethylamine is formed during the disinfection of water and sewage with chlorine, however, the presence of NDMA in drinking waters was reported in the 1980's and 1990's (Jobb et al. 1995). The results, obtained by Choi et al. (Choi et. al., 2002) and Mitch et al. (Mitch et al., 2002 and Mitch et al., 2003), indicated the formation of NDMA as the result of chlorination of water containing dimethylamine (DMA) and ammonia ions with chlorine. In 2003 Gerecke et al. reported the formation of N-nitrosodimethylamine as a result of the reaction of NOM with chlorine (Gerecke et al., 2003).

The results of research carried out by Andrzejewski et al. indicate that NDMA is formed not only as the result of chlorination with chlorine but probably also with chlorine dioxide (Andrzejewski et al., 2005b). The results also revealed, that chlorination of water containing methylethylamine (MEA) and diethylamine (DEA) in the presence of ammonia ions results in the formation of $\mathrm{N}$-nitrosomethylethylamine (NMEA) and $\mathrm{N}$ nitrosodiethylamine (NDEA), respectively (Andrzejewski et al., 2005a). Consequently, NMEA and NDEA joined the group of disinfection by-products, which are thought to have an effect on human health.

In the light of the above, it is of utmost importance to establish analytical techniques for the determination of $\mathrm{N}$-nitrosamines in water at levels of nanograms per liter.

\subsection{The compound's structure vs. available analytical techniques}

Determination of $\mathrm{N}$-nitrosamines as NDMA, NMEA and NDEA in water is very difficult, because they are present in water at concentrations of a few $\mathrm{ng} \mathrm{I}^{-1}$ and due to the low maximum admissible concentration in water, which was established for these compounds. Additionally NDMA, NMEA and NDEA are characterized by an unfavorably low water/octanol partition coefficient.

The NDMA, NMEA and NDEA structures of Fig.1 are shown.
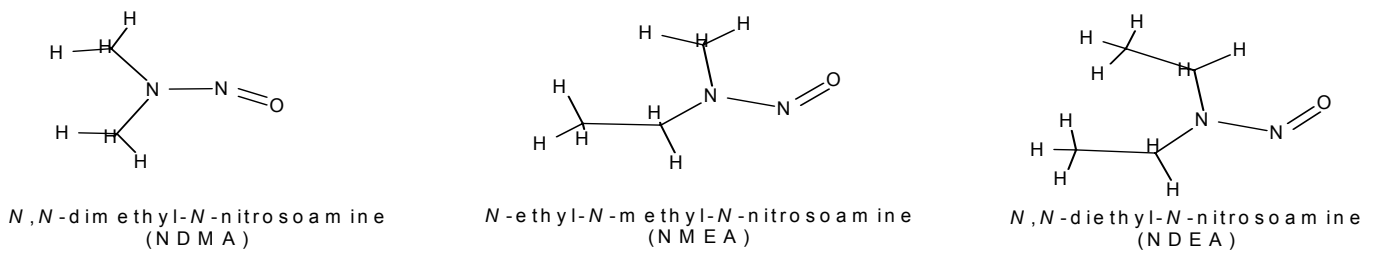

Figure1. NDMA, NMEA and NDEA structures.

The water/octanol partition coefficients for NDMA, NMEA and NDEA are $\log \mathrm{P}_{\mathrm{o} / \mathrm{w}}=-0.57$, 0.04 and 0.48 , respectively (ChemFinder, 2005). An investigation of the structure of the NDMA molecule suggests that the following detection techniques can be used. The presence of an $\mathrm{N}=\mathrm{O}$ double bond allows application of a UV-VIS detector in an HPLC technique as well as a photo ionization detector (PID) in a GC technique. On the other hand, the presence of two atoms of nitrogen in the nitrosamine molecule makes possible the use of a nitrogen-phosphorus detector (NPD) or a chemiluminescence nitrogen detector (CLD). An application of a derivatization technique in nitrosamine analysis makes the range of applied detectors even wider. 
The usage of MS detection is unquestionable, however, one has to take into account the limitations resulting from poor fragmentation, at least in the case of NDMA (See Fig. 2).

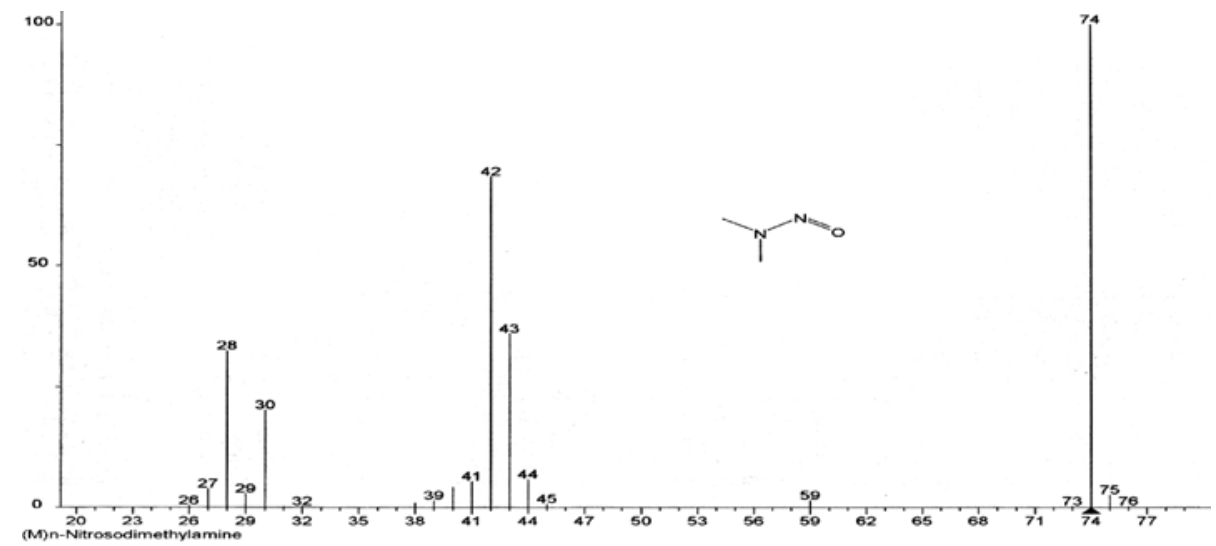

Figure 2. NDMA spectrum (electron ionization)

Only three ions of NDMA can be used in the analysis of this compound. These are: ion $\mathrm{m} / \mathrm{z}=42, \mathrm{~m} / \mathrm{z}=43$ and molecular ion $\mathrm{m} / \mathrm{z}=74$. It has to be emphasized, however, that the lower $\mathrm{m} / \mathrm{z}$ ions, are not specific enough to be used for identification. Thus, even the MS-SIM technique does not guarantee unambiguous qualitative identification of NDMA, particularly because this compound is relatively volatile and shows a short retention time in the GC technique. The problem of qualitative identification of low molecular nitrosamines is typical for applying all the detectors mentioned above. It can be omitted if a high-resolution mass detector is employed, however, none of the methods based on applying this detector type, should be regarded for common use.

The problem of nitrosamine identification, especially in the case of NDMA, can be solved, by means of nitrosamine derivatization. From this point of view, reaction with the $N=O$ group would be the most effective derivatization procedure. Unfortunately, the N-N bond is the weakest one in nitrosamine structure, so that derivatization procedure leads to cleavage of the $\mathrm{N}-\mathrm{N}$ bond and thus nitrosamines are analyzed as corresponding secondary amines. Since secondary amines are precursors of corresponding nitrosamines, all analytical methods, which are based on $\mathrm{N}-\mathrm{N}$ bond cleavage and analysis of secondary amines, which arise before nitrosamine separation, have to be rejected. Determinations of the concentration of nitroso groups, which are formed after N$\mathrm{N}$ bond cleavage is another derivatization path in nitrosamine analysis, however, until now, application of Griess reagent, for example, results in an insufficient detection limit. (Bellec et. al. 1996).

It is self-defined, that the analytical method has to assure nitrosamine identification with high probability. On the other hand, LOD methods should be lower than the maximum admissible level and as well as the concentration of nitrosamine in water

Due to insufficient detector response factors, the preconcentration step, as part of these methods, can occur and an analyte concentration factor should range from a thousand to several thousand. Additionally, application of an analyte cleaning procedure can be considered optionally.

Several analytical methods, which, in the author's opinion, meet the requirements for nitrosamine identification as well as for LOD, both at a level below the maximum admissible level and nitrosamine concentration in water, are described below. Almost all the following analytical methods are based on application of SPE as a preconcentration technique and the majority of them employ a mass detector as the detection system.

3.3. Analytical methods for NDMA determination in water.

A standardized method for nitrosamine analysis in water was established for the USA by US EPA Method 521 (EPA Document \# EPA/600/R-05/054) and referees for seven nitrosamines, i.e. N-nitrosodimethylamine (NDMA), N-nitrosomethylethylamine (NMEA), 
$\mathrm{N}$-nitrosodiethylamine (NDEA), N-nitrosopyrrolidine (NPyr), N-nitrosopiperidine (NPip), Nnitroso-n-dipropylamine (NDPA) and N-nitroso-n-dibutylamine (NDBA).

The method standardized by the USEPA is based on applying the SPE technique for sample preconcentration, where the concentrated sample is analyzed by means of a GCMS/MS system with methanol or acetonitrile chemical ionization at large volume injection. A water sample volume of $500 \mathrm{ml}$ was passed through an SPE column filled with coconut charcoal. Prior to concentration procedure, water samples were dechlorinated and NDMA-d6 as surrogate standard (SS) was added. The water sample was passed through the SPE column and after finishing the filtration procedure, and analyte from the SPE column was eluted with dichloromethane. The dichloromethane extracts were concentrated, enriched with NDPA-d14 as internal standard (IS) and adjusted to their final volume with dichloromethane.

Samples containing nitrosamines were chromatographically separated using gas chromatography technique coupled with a tandem mass selective detector, operating in $\mathrm{Cl}$ mode, with methanol or acetonitrile as the reagent gas. $[\mathrm{M}+1]^{+}$ions were selected mainly as precursor ions. The following product ions (quantification ions) were chosen for particular nitrosamines: for NDMA $-\mathrm{m} / \mathrm{z}=43$ (methanol as $\mathrm{Cl}$ reagent) and $\mathrm{m} / \mathrm{z}=56$ (acetonitrile as $\mathrm{Cl}$ reagent), for NMEA and NDEA $\mathrm{m} / \mathrm{z}=61$ (61) and $\mathrm{m} / \mathrm{z}=75$ (75), respectively.

Method detection limits obtained for the seven nitrosamines (mentioned above) were very low and ranged from $0.26 \mathrm{ng} \mathrm{l}^{-1}$ for NDEA to $0.66 \mathrm{ng} \mathrm{l}^{-1}$ for $\mathrm{N}$-nitrosopiperidine. For $\mathrm{N}$ nitrosodimethylamine (NDMA) and N-nitrosodiethylamine (NMEA), method detection limits obtained were $0.28 \mathrm{ng} \mathrm{I}^{-1}$.

Other analytical methods allowed only the determination of NDMA (Taguchi et al., 1994, Tomkins et al., 1996, and Raksit et al, 2001) or additionally other nitrosamines like nitrosomethylethylamine (NMEA), N-nitrosodiethylamine (NDEA), N-nitrosopyrrolidine (NPyr), N-nitrosopiperidine (NPip), N-nitrosomorpholine (NMor), N-nitroso-ndipropylamine (NDPA) and N-nitroso-n-dibutylamine (NDBA) (Charrois et al., 2004) or Nnitrosodiethylamine (NDEA), N-nitrosopyrrolidine (NPyr), N-nitrosopiperidine (NPip) and N-nitrosomorpholine (NMor) (Perez-Ruiz et al., 2005).

The volume of water samples ranged from $250 \mathrm{ml}$ (Perez-Ruiz et al., 2005) to $1000 \mathrm{ml}$ (Taguchi et al., 1994 and Tomkins et al., 1996). NDMA-d6, as a surrogate standard, in an isotope dilution technique, employing the water samples (Charrois et al., 2004, Raksit et al., 2001 and Taguchi et al., 1994).

SPE techniques were applied mainly for the water sample preconcentration step. Charrois et al. (Charrois et al., 2004) proposed application of a three layer bed SPE column filled with LiChrolut EN (bottom) followed by Ambersorb 572 (middle) and glass wool (top). Others like Perez-Ruiz et al. (Perez-Ruiz et al., 2005) used Strata X as an adsorbent in a fully automatic system. Application of membrane extraction disks in an SPE technique was proposed by Tomkins et al. (Tomkins et al., 1996). In this method, water sample volume was passed through two membrane extraction disks filled with C18 (upper disk) and carbon-base Empore adsorbent (lower disk). The reverse phase C18 disk removes nonpolar water-insoluble compounds. The water sample was simultaneously filtered through both disks and after filtration, analyte from the lower Empore containing disk, was extracted. Taguchi et al. (Taguchi et al., 1994) used an SPE technique with Ambersorb 572, but in this method adsorbent was added to the water sample and the extraction procedure was carried out by means of sample shaking, followed by removal of adsorbent from the water sample by filtration.

Raksit et al. (Raksit et al., 2001) proposed application of an LLE technique for sample preconcentration. The water sample was extracted with dichloromethane. Dichloromethane extract was concentrated in a rotary evaporator.

Dichloromethane was used in the SPE technique as an extraction agent by almost all authors quoted above. An application of acetone alone was suggested by Perez-Ruiz et al. (Perez-Ruiz et al., 2005) and was probably connected with the application of RP- 
HPLC as a separation technique. Prior to extraction with dichloromethane and after an analyte concentration procedure, the SPE bed was vacuum dried (Charrois et al., 2004 and Taguchi et al., 1994) or washed with ultrapure water and air. (Perez-Ruiz et al., 2005). This step is, according Charrois et al. (Charrois et al., 2004), critical for proper analyte elution.

Dichloromethane extracts were often enriched with internal standards like NDEA (Raksit et al., 2001) or NDPA-d14 (Charrois et al., 2004), however methods without application of any standard were proposed, as well (Tomkins et al., 1996 and Perez-Ruiz et al., 2005). In the case of methods described by Tomkins et al. (Tomkins et al., 1996 ) and PerezRuiz et al. (Perez-Ruiz et al., 2005), it should be emphasized that because of application of detectors (other than MS), NDMA-d6 could not be applied as a surrogate standard. Dichloromethane extracts, some of them after internal standard addition or/and methanol (Charrois et al., 2004), were concentrated to final volume under a stream of nitrogen in a room with a slightly higher temperature. Charrois et al. calculated the extract concentration factor as 2500 , with a sample volume of $500 \mathrm{ml}$ and a final volume of dichloromethane extract of $200 \mu \mathrm{l}$ (Charrois et al., 2004).

Nitrosamines containing dichloromethane extracts were chromatographically separated, using mainly a gas chromatography technique coupled with a high-resolution mass selective detector. Taguchi et al. (Taguchi et al., 1994) applied GC coupled with a highresolution mass selective detector, operating in a negative ionization SIM mode. The molecular ion of $\mathrm{m} / \mathrm{z}=74.048$ and $\mathrm{m} / \mathrm{z}=80.086$ were selected for NDMA and NDMA-d6 both for identification and quantification, respectively. Method detection limits obtained for $\mathrm{N}$-nitrosodimethylamine (NDMA) is $2.4 \mathrm{ng} \mathrm{l}^{-1}$. The same system (i.e. gas chromatography technique) was used by Raksit et al. (Raksit et al., 2001) (i.e. gas chromatography technique), however, the method was coupled with a mass selective detector (low resolution), operating in the SIM mode. The method detection limit obtained for $\mathrm{N}$ -

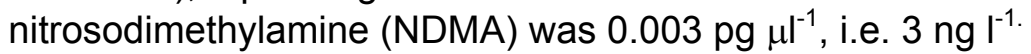

Gas chromatography separation techniques coupled with a mass selective detector, operating in the $\mathrm{PCl}$ mode, with ammonia as the reagent gas was proposed by Charrois et al. (Charrois et al., 2004).

Positive chemical ionization, as opposed to the electron ionization process, is "softer" and results in less molecular fragmentation. In the method described, methanol, which is commonly used in $\mathrm{PCl}$ mode, was replaced with ammonia. Ammonia applied as a gaseous reagent results in better selective ionization, lower background noise as well as increased analyte sensitivity. $[\mathrm{M}+18]^{+}$ions were selected as target ions and $[\mathrm{M}+1]^{+}$ions as qualifier ions. Method detection limits obtained for the eight nitrosamines (mentioned above) were low and ranged from $0.4 \mathrm{ng} \mathrm{l}^{-1}$ for $\mathrm{N}$-nitrosopyrrolidine to $1.6 \mathrm{ng} \mathrm{l}^{-1}$ for $\mathrm{N}$ nitrosopiperidine with an injection volume of $1 \mu \mathrm{l}$. For $\mathrm{N}$-nitrosodimethylamine (NDMA), Nnitrosomethylethylamine (NMEA), N-nitrosodiethylamine (NDEA), i.e. nitrosamines with the lowest maximum admissible concentrations according USEPA directive, MDL were $1.6 \mathrm{ng} \mathrm{I}^{-1}, 1.2 \mathrm{ng} \mathrm{I}^{-1}$, and $1.3 \mathrm{ng} \mathrm{I}^{-1}$, respectively.

Gas chromatography technique was also applied by Tomkins et al., however, it was coupled with chemiluminescent nitrogen detector. The method detection limit obtained for $\mathrm{N}$-nitrosodimethylamine (NDMA) was $3 \mathrm{ng} \mathrm{l}^{-1}$ with an analyte recovery of $57 \%$ (Tomkins et al., 1996).

Another analytical technique with an alternative type of detector was developed by PerezRuiz et al. (Perez-Ruiz et al., 2005). This fully-automatic method was based on application of HPLC-CLD in a system with post-column photolysis and derivatization with tris(2,2'-bipirydyl) ruthenium(III). Prior to derivatization and CLD detection, individual nitrosamines were separated by means of HPLC technique.

Nitrosamines containing extracts were chromatographically separated using an HPLC technique with an ODS column coupled with a photohydrolytic reactor, where the nitrosamines were converted into their corresponding amines. The effluent from the photolysis coil was directed to one of the flow cell ports, where it was mixed with on-line 
generated tris(2,2'-bipirydyl) ruthenium(III). The post-reaction mixture was analyzed with a chemiluminescent detector.

Method detection limits obtained for five nitrosamines (mentioned above) ranged from $0.10 \mathrm{ng} \mathrm{I}^{-1}$ to $3.0 \mathrm{ng} \mathrm{I}^{-1}$.

The list of analytical methods allowing determination of NDMA as well as other nitrosamines with high identification credibility and LOD below both maximum admissible levels and concentration in environmental water samples, is very short. Several analytical methods, which meet the requirements described above are presented in this paper.

Analytical methods, consisting of an SPE concentration system, followed by GC separation coupled with mass detection and positive chemical ionization, seem to be the most reliable methods for nitrosamine determination in water samples. An application of a tandem MS system can additionally increase NDMA identification reliability.

At the present time, determination of nitrosamines with an SPE/GC-CI-MS system should be considered as the most reliable method. Other analytical paths, that can lead to improved nitrosamine determination should not, however, be neglected.

\section{CONCLUSION}

The WHO has not established maximum admissible concentrations of $M X$ in water (WHO) but has pointed out that health based maximum concentrations of $\mathrm{MX}$, associated with a $10^{-5}$ risk level, was $1.8 \mu \mathrm{g} \mathrm{I}^{-1}$. On the other hand several methods have been developed, which allow determination of MX at ppt concentrations. Thus, in the authors' opinion, further development of MX analytical methods are not to be expected.

The USEPA standardized method for NDMA determination as well as the majority others described above are reliable, but on the other hand, complicated. The interest shown concerning NDMA as a disinfection by-product has increased, thus, contrary to MX, further development of NDMA analytical methods are to be expected. The determination method simplicity have to be expected as the aim of further investigation.

\section{REFERENCES}

Andrzejewski P. (1999), PhD thesis, A. Mickiewicz University of Poznań (in Polish)

Andrzejewski P., Nawrocki J., (2003) MX and other potentially hazardous chlorinated by-products, in Handbook of Environmental Chemistry, 5, Part G: Haloforms and Related Compounds in Drinking Water, Nikolaou A. (ed.), Springer Verlag, Berlin.

Andrzejewski P. Kasprzyk-Hordern B., Nawrocki J., (2005) The N-nitrosomethylethylamine (NMEA), new disinfection byproducts, formation during water disinfection with chlorine, Proc. $9^{\text {th }}$ International Conference on Environmental Science and Technology, Rhodes, Greece, accepted.

Andrzejewski P., Kasprzyk-Hordern B., Nawrocki J., (2005), The hazard of N-nitrosodimethylamine (NDMA) formation during water disinfection with strong oxidants, Desalin. 176, 37-45

Asplund D., Kronberg L., Sjoholm R., Munter T., (1995), Reactions of mucochloric acid with adenosine; formation of 8-( $\mathrm{N}^{6}$ - adenosinyl)ethenoadenosine derivatives, Chem. Res. Toxicol. 8, 841-846.

Bellec C, Cauvin J.M. Salaun M.C. (1996), Analysis of N-nitrosoamines by high-performance liquid chromatography with post-column photohydrolysis and colorimetric detection, $J$. Chromatogr. A, 727, 83-92.

Blacklund P., L. Kronberg L., Tikkanen L., (1988), Formation of Ames mutagenicity and of the strong bacterial mutagen 3-chloro-4-(dichloromethyl)-5-hydroxy-2(5H)-furanone and other halogened compounds during disinfection of humic water, Chemosphere, 17, 1329-1336.

Blacklund P., Wondergem E., Voogd K., De Jong A., (1989), Influence of chlorination pH and chlorine dose on the formation of mutagenic activity and the strong bacterial mutagen 3-chloro-4(dichloromethyl)-5-hydroxy-2(5H)-furanone (MX) in water, Chemosphere, 18, 1093-1112.

Bruner F., (1993) Gas Chromatographic Environmental Analysis. VCH Publishers Inc., New York

Charles M.J., Chen G., Kanniganti R., Marbury G.D., (1992), High-Resolution Mass Spectrometry Method for the Analysis of 3-Chloro-4-(Dichloromethyl)-5-Hydroxy-2(5H)-Furanone in Waters, Environ. Sci. Technol., 26, 1030-1035 
Charrois J.W.A., Arend M.W., Froese K. L., Hrudey S.W. (2004), Detecting N-nitrosamines in drinking water at nanogram per liter levels using ammonia positive chemical ionization, Environ. Sci. Technol. 38, 4835-4841.

Chengyong Y., Zhuo C., Huixian Z., Junhe L., Jinqi Z., (2000), Factors on the formation of strong mutagen (3-chloro-4-(dichloromethyl)-5-hydroxy-2(5H)-furanone) MX by chlorination of syringaldehyde., Water Res., 34, 4313-4317.

Choi J., Valentine R.L. (2002), Formation of N-nitrosodimethylamine (NDMA) from reaction of monochloroamine : a new disinfection by-product; Wat. Res., 36, 817-824.

Conrad D.J., Huch P.M., (1994), Impact of new pulp mill technology on chlorination by-products formation in drinking water treatment plants. Proc. - Annu. Conf., Am. Water Works Assoc., Vegreville, Canada.

Franzen R., Kronberg L. (1994), Determination of chlorinated 5-methyl-5-hydroxyfuranones in drinking water, in chlorinated humic water, and in pulp bleaching liquor. Environ. Sci. Technol., 28, 2222-2227.

Fukui S., Yoshimira Y., Ogawa S., Hanazaki Y., (1990), Formation of Non-volatile, Potent Mutagens in Domestic Sewage by Chlorination. Chemosphere, 21, 705-716.

Gerecke A.C., Sedlak. D.L, (2003), Precursors of N-nitrosodimethylamine in natural waters, Env. Sci. Tech., 37, 1331-1336.

Gunnison D, Zappi M.E., Teeter C., Pennington J., Bajpai R, (2000), Attenuation mechanisms of $\mathrm{N}$-nitrosodimethylamine at operating intercept and treat groundwater remediation system, J. Hazard. Mat. B73, 179-197

Holmbom B.R., Voss R.H., Mortimer R.D., Wong A., (1984), Fractionation, isolation and characterization of Ames mutagenic compounds in kraft chlorination effluents, Environ. Sci. Technol., 18, 333-337

Horth, H., (1990), Identification of mutagens in drinking water. J.Fr.Hydrolog., 21, 135-145.

Huixian Z., Junhe L., Zhuo C., Chengyong Y., Jinqi Z., Wen Z. (2000), Screening the precursors of strong mutagen [3-chloro-4-(dichloromethyl)-5-hydroxy-2(5H)-furanone] MX from chlorinated water, Water Res., 34, 225-229.

Jobb D.B., Hunsinger R.B., Meresz O., Taguchi V.Y. (1995), Proc. Am. Water Works Assoc. Water Qual. Technol. Conf. Denver, CO, USA.

Kronberg L., Christman R.F., Singh R., Ball L.M., (1991), Identification of oxidized and reduced forms of the strong bacterial mutagen (Z)-2-chloro-3-(dichloromethyl)-4-oxobutenoic acid (MX) in extracts of chlorine-treated water, Environ. Sci. Technol., 25, 99-104.

Kronberg L., Holmbom B., Reunanen M., Tikkanen L., (1988), Identification and quantification of the Ames mutagenic compound 3-chloro-4-(dichloromethyl)-5-hydroxy-2(5H)-furanone and of its geometric isomer (E)-2-chloro-3-(dichloromethyl)-oxobutenoic acid in chlorine-treated humic water and drinking water extracts, Environ. Sci. Technol., 22, 1097-1110.

Kronberg L., Holmbom B., Tikkanen L., In Ed. By Jolley R.L., Condie L.W., Johnson J.D., Katz S., Minear R.A., Mattice J.S., Jacobs V.A., (1987), Identification of the strong mutagen 3 -chloro4-(dichloromethyl)-5-hydroxy-2(5H)-furanone, and of its geometric isomer E-2- chloro-3(dichloromethyl)-4-oxobutenoic acid in mutagen fractions of chlorine-treated humic water and in drinking waters, Water Chlorination, 6, 137-146.

Lalonde R.T., Cook G.P., Perakyla H., Dence C.W., (1991), Effect on mutagenicity of the stepwise removal of hydroxyl group and chlorine atoms from 3-chloro-4-(dichloromethyl)-5-hydroxy$2(5 \mathrm{H})$-furanone: ${ }^{13} \mathrm{C}$ NMR chemical shifts as determinants of mutagenicity., Chem. Res. Toxicol., 4, 35-43.

Lalonde R.T., Cook G.P., Perakyla H., Lin Bu, (1994), Structure-activity relationships of bacterial mutagens related to 3-chloro-4-(dichloromethyl)-5-hydroxy-2(5H)-furanone: An emphasis on the effect of stepwise removal of chlorine from the dichloromethyl group., Chem. Res. Toxicol., 4, 540-545

Lalonde R.T., Lin Bu, Henwood A., Fiumano J., Zhang L., (1997), Bromine-, chlorine-, and mixed halogen-substituted 4-methyl-2(5H)-furanones: Synthesis and mutagenic effects of halogen and hydroxyl group replacements, Chem, Res. Toxicol., 10, 1427-1436.

Lalonde R.T., Perakyla H., Hayes M.P., (1990), Potentially mutagenic, chlorine-substituted 2(5H)furanones: Studies of their synthesis and NMR properties, J. Org. Chem., 55, 2847-2855. 
Langvik V.A., Hormi O., Tikkanen L., Holmbom B., (1991), Formation of the mutagen 3-chloro-4(dichloromethyl)-5-hydroxy-2(5H)-furanone (MX) and related compounds by chlorination of phenolic compounds, Chemosphere, 22, 547-555.

Meier J.R., Khnohl R.B., Coleman W.E., Ringhand H.R., Munch J.W., Kaylor W.H., Streicher R.P., Kopfler F.C. (1987), Studies on the potent bacterial mutagen, : aqueous stability, XADrecovery and analytical determination in drinking water and in chlorinated humic acid solution, Mutat. Res., 189, 363-373

Meier J.R., Khnohl R.B., Coleman W.E., Ringhand H.R., Munch J.W., Kaylor W.H., Streicher R.P., Kopfler F.C., (1987), Studies on the potent bacterial mutagen: aqueous stability, XADrecovery and analytical determination in drinking water and in chlorinated humic acid solution, Mutat. Res., 189, 363.

Method 521: Determination of nitrosamines in drinking water by solid phase extraction and capillary column gas chromatography with large volume injection and chemical ionization tandem mass spectrometry (MS/MS), Ver.1.0, EPA Document \# EPA/600/R-05/054

Mitch W.A., Sedlak D.L. (2002), Formation of N-nitrosodimethylamine (NDMA) from dimethylamine during chlorination ; Env. Sci. Tech., 36, 588-595.

Mitch W.A., Sharp J.O, Trussell R.R., Valentine R.L. Alvarez-Cohen L., Sedlak D.L. (2003), Nnitrosodimethylamine (NDMA) as drinking water contaminant: Review, Environ. Eng. Sci. 20, 389-404

Nawrocki J., Andrzejewski P., Jeleń H., Kronberg L., (1998), Propanols as derivatization reagents for determination of MX (3-chloro-4-(dichloromethyl)-5-hydroxy-2(5h)-furanone) in water., Chem. Anal. (Warsaw), 43, 687-692

Nawrocki J., Andrzejewski P., Jeleń H., Wassowicz E., (2001), Derivatization of the mutagen MX (3-chloro-4(dichloromethyl)-5-hydroxy-2(5H)-furanone) with butyl alcohols prior to GC-MS analysis, Water Res., 35(8), 1891-1896.

Nawrocki J., Andrzejewski P., Jeleń P., (2001), Application of sec-butanol for derivatization of hydroxyfuranones, JAOAC, 84, 1802-1808.

Nawrocki J., Andrzejewski P., Kronberg L., Jeleń H., (1997), New derivatization method for the determination of 3-chloro-4-(dichloromethyl)-5-hydroxy- $2(5 \mathrm{H})$-furanone in water , $J$. Chromatogr. A, 790, 242-

Nawrocki J., Andrzejewski P., Kronberg L., Jeleń H., (1999), A new derivatization method for a determination of MX and related hydroxyfuranones in water, Toxicol. Environ. Chem., 69, 241-253.

Nawrocki J., Andrzejewski P., Kronberg L., Jeleń H., (2000), Determination of Hydroxyfuranones in Water by Derivatization with 2- Propanol, Chem. Anal. (Warsaw), 45, 215-221

Ogawa S., Kita H., Hanasaki Y., Fukui S., Kami H., (1993), Determination of the Potent Mutagen 3Chloro-4-(Dichlorometylo)-5-Hydroksy-2(5H)-Furanon (MX) in Water by Gas Chromatography with Electron Capture Detection., J. Chromatogr., 643, 221-226

Onstad G.D., Weinberg H.S., (2005), Evaluation of stability and analysis of halogenated furanones in disinfected drinking waters, Anal. Chimica Acta, 534, 281-292.

Perez-Ruiz T., Martinez-Lozano C., Tomas V., Martin J., (2005), Automated solid-phase extraction and high-performance liquid chromatographic determination of nitrosamines using postcolumn photolysis and tris(2,2"-bipiridyl) ruthenium(III) chemiluminescence, J. Chromatogr A, 1077, 49-56.

Raksit A., Johri S (2001), Determination of N-Nitrosodimethylamine in environmental aqueous samples by isotope-dilution GC-MS-SIM, J. of AOAC International, 84, 14131419Rantakokko P., Yritys M., Vartiainen T., (2004), Matrix effects in gas chromatographic-mass spectrometric determination of brominated analogues of 3-chloro4-(dichloromethyl)-5-hydroxy-2(5H)-furanone., J. Chromatogr A, 1028, 179-188.

Rezemini A.L., Vaz J.M., Carvalho L.R.F., (2002), Gas chromatographic-mass spectrometric method for quantification of 3-chloro-4-(dichloromethyl)-5-hydroxy-2(5H)-furanone in chlorinated water samples, J. Chromatogr A, 972, 259-267.

Richardson S.D. (2003), Disinfection by-products and other emerging contaminants in drinking water, Trends in Analytical Chemistry, 22, 666-684

Schenck K.M., Meier J.R., Ringhand H.P., Kopfler F.C., (1990), Recovery of 3-Chloro-4(Dichloromethyl)-5-Hydroxy-2(5H)-Furanone from Water Samples on XAD Resins and the Effect of Chlorine on Its Mutagenicity, Environ. Sci. Technol., 24, 863-867 
Suzuki N., Nakanishi J., (1995), Brominated analogues of MX (3-chloro-4-(dichloromethyl)-5hydroxy-2(5H)-furanone) in chlorinated drinking water., Chemosphere, 30, 1557-1564

Taguchi V.Y., Jenkins S.W.D., Wang D.T., Palmentier J.F.P, Reiner E.J. (1994), Determination of $\mathrm{N}$-nitrosodimethylamine by isotope dilution, high-resolution mass spectrometry, Can. J. Appl. Spectrosc. 39, 87-93

Tomkins B.A., Griest W.H. (1996), Determination of N-nitrosodimethylamine at part-per-trillion concentrations in contaminated groundwaters and drinking waters featuring carbob-based membrane extraction disks, Anal. Chem. 68, 2533-2540

Umetani T., Morizane K., (1997), Osaka-shi Suidokyoku Suishitsu Shikensho Chosa Kenkyu narabini Shiken Seiseki, 48, 17-22

Vartiainen T., Liimatainen A., Jaaskelainen S., Kauranen P. (1987), Comparison of solvent extractions and resin adsorption for isolation of mutagenic compounds from chlorinated drinking water with high humus content, Mutat. Res., 21, 773-779.

Vartiainen, T., Heiskanen, K., Lötjönen, S., (1991), Analysis of some chemical properties of MX (3-chloro-4-(dichloromethyl)-5-hydroxy-2 $(5 \mathrm{H})$-furanone), the potent drinking water mutagen. Fres. J. Anal. Chem., 340, 230-233.

WHO, Guidance for Drinking water quality, Third Edition WHO, Geneva 2004.

WHO, Guideliness for drinking water quality, draft, http://www.who.int/water sanitation health/ 2003.

Wunsch, K-H. Miethchen R., Ehlers D. (1979), Organische Chemie Grundkurs, PWN.

www.chemfinder.com

www.epa.gov/iris/subst/index.html

Zwiener C., Kronberg L., (2001), Determination of the strong mutagen 3-Chloro-4(Dichloromethyl)-5-Hydroxy-2(5H)-Furanone (MX) and its analogues by GC-ITD.-MS-MS., Fres. J. Anal. Chem., 371, 591-603. 